\title{
O AMBIENTE REMOTO COMO FERRAMENTA PROMOTORA DE PRÁTICAS LABORATORIAIS NO ENSINO DE TRIGONOMETRIA EM CURSOS DE LICENCIATURA EM MATEMÁTICA
}

\author{
THE REMOTE ENVIRONMENT AS A TOOL THAT PROMOTES LABORATORY PRACTICES IN \\ THE TEACHING OF TRIGONOMETRY IN UNDERGRADUATE COURSES IN MATHEMATICS \\ EL ENTORNO REMOTO COMO HERRAMIENTA QUE PROMUEVE PRÁCTICAS DE \\ LABORATORIO EN LA ENSEÑANZA DE TRIGONOMETRÍA EN CURSOS DE PREGRADO EN \\ MATEMÁTICAS
}

\section{Ana Carolina Costa \\ Pereira \\ (iD) 9 \\ Doutorado em Educação (UFRN) \\ Docente do Pós-Graduação em \\ Educação (PPGE/UECE) e do Pós- \\ Graduação em Ensino de Ciências \\ e Matemática (PGECM/IFCE) \\ carolina.pereira@uece.br}

\section{Gisele Pereira Oliveira \\ (iD) 9}

Mestrado em ensino de Ciências e

Matemática (UFC)

Professora efetiva da educação

básica da Secretaria de Educação

do Estado do Ceará (SEDUC)

Discente do Programa de Pós-

graduação em Educação

(PPGE/UECE)

gisele.oliveira@aluno.uece.br

\begin{abstract}
Resumo
Esse artigo aponta uma experiência realizada durante o ano letivo de 2020, em tempos de pandemia do COVID 19, na disciplina de Laboratório de Ensino de Trigonometria (LET), que se propôs a experimentação de práticas com professores em formação inicial do curso de licenciatura em Matemática da Universidade Estadual do Ceará. Com isso, tem-se o intuito de apresentar um relato de experiência vivenciado nesta, via ambiente virtual, Google Meet e Zoom, em ensino remoto. Nessa direção, fez-se uso de uma abordagem qualitativa, por se apropriar quanto ao desafio da realização de práticas de trigonometria remotamente. Amparou-se, ademais, na Sequência Fedathi, que fundamentou mediante a tomada de posição, maturação, solução e prova de sequências didáticas para o desenvolvimento de conhecimentos trigonométricos. E, portanto, visualizou-se que existem desafios significativos quanto ao uso de tecnologias digitais no ensino de Matemática, mas que podem ser minimizados diante de formações e subsídios tecnológicos.

Palavras-chave: Laboratório de Ensino de Trigonometria.

Ensino Remoto. Tecnologias Digitais da Informação e

Comunicação. Ensino de Matemática.
\end{abstract}

Recebido em: 12 de março de 2021.

Aprovado em: 13 de maio de 2021.

Como citar esse artigo (ABNT):

PEREIRA, Ana Carolina Costa; OLIVEIRA, Gisele Pereira. O ambiente remoto como ferramenta promotora de práticas laboratoriais no ensino de trigonometria em cursos de licenciatura em Matemática. Revista Prática Docente, v. 6, n. 2, e027, 2021.

http://doi.org/10.23926/RPD.2021.v6.n2.e027.id1076 


\section{Abstract}

This article points to an experience carried out during the academic year of 2020, in times of the pandemic of COVID 19, in the discipline of Laboratory of Teaching of Trigonometry (LET), which proposed the experimentation of practices with teachers in initial formation of the degree course in Mathematics at the State University of Ceará. With that, the intention is to present an account of experience lived in this, via virtual environment, Google Meet and Zoom, in remote education. In this sense, a qualitative approach was used, as it appropriated the challenge of performing trigonometry practices remotely. In addition, it was supported by the Fedathi Sequence, which was based on the taking of position, maturation, solution and proof of didactic sequences for the development of trigonometric knowledge. And, therefore, it was seen that there are significant challenges regarding the use of digital technologies in the teaching of Mathematics, but that they can be minimized in the face of technological training and subsidies.

Keywords: Trigonometry Teaching Laboratory. Remote Teaching. Digital Technologies of Information and Communication. Mathematics teaching.

\section{Resumen}

Este artículo apunta a una experiencia realizada durante el curso académico 2020, en tiempos de la pandemia de COVID 19, en la disciplina de Laboratorio Docente de Trigonometría (LET), que proponía la experimentación de prácticas con docentes en formación inicial de la titulación. curso de Matemáticas en la Universidad Estatal de Ceará. Con eso, la intención es presentar un relato de la experiencia vivida en este, a través del entorno virtual, Google Meet y Zoom, en educación remota. En este sentido, se utilizó un enfoque cualitativo, ya que se apropió del desafío de realizar prácticas de trigonometría de forma remota. Además, se apoyó en la Secuencia Fedathi, que se basó en la toma de posición, maduración, solución y prueba de secuencias didácticas para el desarrollo del conocimiento trigonométrico. Y, por tanto, se vio que existen retos importantes en cuanto al uso de las tecnologías digitales en la enseñanza de las Matemáticas, pero que se pueden minimizar ante la formación tecnológica y las subvenciones.

Palabras clave: Laboratorio de enseñanza de trigonometría. Enseñanza remota. Tecnologías digitales de información y comunicación. Enseñanza de las matemáticas. 


\section{INTRODUÇÃO}

Em meio ao século XXI e imersos a contextos de avanços tecnológicos, percebe-se que a divulgação e o acesso de informações variadas se estabelecem em rápida velocidade via meios de comunicação digital disponíveis nesta época. E, diante deste cenário, ver-se a possibilidade de elaboração, construção e experimentação de diferentes práticas sociais a partir destes recursos.

Nessa direção, visualiza-se na Educação, consoante a Javaroni e Zampieri (2019), que desde o século XX, já percebia-se discussões e pesquisas acerca do uso de tecnologias digitais no ambiente escolar e acadêmico, em especial, discutia-se em grupos de pesquisas de informática e mídias na Educação.

Com isso, reforça-se o que Oliveira (2018) destacou por necessidade de formação de professores e profissionais da Educação para constituição de fluência no uso de tecnologias nos processos educacionais de ensino. E, desse modo, para essa ocasião, ressalta-se a usabilidade destes para o ensino de Matemática, nos variados níveis e modalidades de ensino.

Nesse contexto, vale reforçar, as exigências já apontadas nos documentos norteadores da Educação em relação ao uso de tecnologias digitais no ensino de saberes do conhecimento, tal como vistos em Brasil (2018), na Base Nacional Comum Curricular (BNCC), e, em Brasil (1997), nos Parâmetros Curriculares Nacionais (PCN).

Em continuidade, viu-se ser essencial para este, a construção do que Sousa (2020) apontou ser uma aliança entre elementos fundantes da experiência via investigação científica. E, de maneira correspondente, constituiu-se para a realização de práticas de ensino, a articulação entre o Laboratório de Ensino de Trigonometria e o uso de Tecnologias Digitais da Informação e Comunicação (TDIC).

Dessa maneira, inquietou-se a refletir sobre a pergunta diretriz de "Como realizar práticas de ensino por meio do Laboratório de Ensino de Trigonometria em um curso de licenciatura em Matemática?’. E, assim, esse artigo tem o intuito de apresentar um relato de experiência vivenciado no ano de 2020, na disciplina de Laboratório de Ensino de Trigonometria (LET), via ambiente virtual, Google Meet $^{1}$ e $\mathrm{Zoom}^{2}$, em modalidade de ensino

\footnotetext{
${ }^{1}$ Google Meet trata-se de um sistema de comunicação virtual na categoria de vídeo, que foi desenvolvido e disponibilizado pelo Google. Para mais informações vide: https://pt.wikipedia.org/wiki/Google Meet.

2 Zoom refere-se a um software usado para reuniões remotamente. Verifique mais informações em: https://pt.wikipedia.org/wiki/Zoom_Video_Communications.
} 
remoto, proposto pelo curso de licenciatura em Matemática da Universidade Estadual do Ceará (UECE).

Nessa perspectiva, Breda (2018) reforça a possibilidade de relação do ensino de Matemática e seus conceitos com às TDIC, em que aponta, que faz-se preciso uma discussão e estudo, no campo da didática da Matemática para avaliar os melhores recursos a serem usados em cada contexto de ensino, buscando-se mediante a estes, a possibilidade de promover o ensino de qualidade e a aprendizagem significativa de saberes.

Esse estudo, caracterizou-se conforme Araújo e Borba (2004) como uma abordagem qualitativa, por permitir-nos perceber e identificar percepções dos sujeitos participantes desta experiência em relação as práticas realizadas no LET. E, também, pautou-se segundo a metodologia Sequência Fedathi, que conforme Pinheiro, Pedrosa e Mendonça (2016, p.6) referisse a realização nas práticas de ensino no LET de "sequência didática em que o professor organiza seu trabalho em quatro fases, que são, tomada de posição, maturação, solução e prova".

Sendo, dessa forma, proposto no curso de licenciatura, práticas de ensino, no LET, em que os professores de Matemática em formação inicial, experimentaram sequências didáticas propostas, consoante a Pinheiro, Pedrosa e Medonça (2016), com a expectativa de conduzir tais sujeitos as fases de tomada de posição, maturação, solução e prova das situações e experiências propostas.

A seguir, o artigo contemplará e discutirá sobre o laboratório de Matemática e ensino em cursos de licenciatura em Matemática, o laboratório de ensino de Trigonometria: conceitos e experimentações, modelo de proposta de laboratório de ensino de Trigonometria, o lócus da pesquisa e suas produções coletivas e algumas notas finais.

\section{LABoratório de MATEMÁtica E ENSino EM CURSOS DE LiCENCIATURA EM MATEMÁtica}

O laboratório de Matemática e Ensino (LME) é um ambiente educacional que, dependendo da concepção de quem atua nele, está direcionado a diversos objetivos. Para Rodrigues e Gazire (2015) essas percepções mudam dependendo dos campos de atuação, ou seja, na Educação Básica e/ou no Ensino Superior. Os autores dispõem de sete tipos de laboratórios: (1) Laboratório como depósito-arquivo; (2) Laboratório como sala de aula; (3) Laboratório como uma disciplina; (4) Laboratório de tecnologias; (5) Laboratório tradicional 
de Matemática; (6) Laboratório como sala ambiente do laboratório de Ensino de Matemática; e (7) Laboratório como agente de formação, ligada a Educação Matemática.

Observando as concepções propostas por Rodrigues e Gazire (2015), a terceira delas está relacionada ao laboratório como uma disciplina no curso de licenciatura em Matemática3. Segundo Oliveira e Kikuchi (2018, p. 810), como disciplina ele é

uma componente curricular de diversos cursos de Licenciatura em Matemática com uma abordagem teórico-prática, ou seja, não é uma simples disciplina para instrumentalizar o futuro professor com atividades, mas sim para abordar temáticas recentes de pesquisa ligadas à Educação Matemática.

Dessa forma, ele é uma poderosa ferramenta que pode proporcionar uma discussão de diversas temáticas ligadas a Educação Matemática, a aspectos relacionados aos documentos oficiais, a história do próprio conteúdo matemático, aos recursos didáticos sejam eles, manipuláveis ou não (tecnológicos), a problemas relacionados ao ensino de Matemática e seus caminhos para solucionarmos, ou seja, é um lugar de reflexão de práticas concebidas em disciplinas que envolvem a área de educação Matemática.

A institucionalização do Laboratório de Matemática e Ensino (LME) na formação inicial do futuro professor de Matemática se deu de forma mais ampliada a partir da publicação das Diretrizes e Bases da Educação Nacional de № 9.394 de 20 de dezembro de 1996 e do documento de Diretrizes Curriculares Nacionais para os Cursos de Matemática, Bacharelado e Licenciatura, CNE/CES 1.302/2001 de 06 de novembro de 2001, e da Resolução CNE/CES no 3, de 18 de fevereiro de 2003.

Em ambos os documentos, o conceito e a aplicabilidade do Laboratório de Matemática e Ensino não estava claro, embora esteja implícito em vários momentos quando se reportam aos estágios supervisionados. Brasil (2001, p. 6, grifo nosso) ressalta que

No caso da licenciatura, o educador matemático deve ser capaz de tomar decisões, refletir sobre sua prática e ser criativo na ação pedagógica, reconhecendo a realidade em que se insere. Mais do que isto, ele deve avançar para uma visão de que a ação prática é geradora de conhecimentos. Nessa linha de abordagem, o estágio é essencial nos cursos de formação de professores (...).

Especificamente no curso de licenciatura em Matemática da UECE, a disciplina de laboratório de Matemática foi agregada a formação no Projeto Político Pedagógico (PPP) de 1998, direcionando 34 horas/aulas, equivalente a 2 créditos. Houve uma atualização em 2007 ,

\footnotetext{
${ }^{3}$ Para uma compreensão melhor do laboratório de Matemática e ensino nos cursos de licenciatura, vide, Bertoni e Gaspar (2006), Pires (2008), Rodrigues (2015), Lorenzato (2012), Bittar E Freitas (2005), Turrioni (2004), entre outros.
} 
mas a disciplina permaneceu, sendo aproveitada o mesmo programa, com carga-horária, prérequisito, ementa e bibliografia do anterior. Nesse projeto, a ementa estava direcionada a "Experiências relacionadas com tópicos de Matemática do Ensino Fundamental e do Ensino Médio" (CEARÁ, 2007, p. 8).

No seu programa, há temáticas pontuais relacionadas a áreas específicas da Matemática, reduzindo assim, a possibilidade de práticas laboratoriais com conteúdos matemáticos: (1) A Matemática como um sistema formal; (2) A Matemática como percepção de regularidades; (3) Algoritmos: multiplicação de números naturais, divisão de números naturais, raiz quadrada, a torre de Hanói; (5) Os números inteiros; (6) Teorema de Pitágoras; (7) Relações métricas no triângulo retângulo; (8) A noção de limite; e (9) Fatoração de trinômios.

As referências, muitas delas estão relacionadas a revistas não científicas, como Revista Nova Escola, Revista Sala de Aula e a Revista do Professor de Matemática, além de livros ligados a temas pontuais como Smith, (1996), Van Cleave (1994), Kurt (1996), Farmer (1996) e Eves (1995). Dessa forma, percebe-se que a carga-horária da disciplina é muito ínfima, implicando em um conteúdo reduzido para um curso de licenciatura em Matemática, não contemplando assim, as grandes áreas da Matemática: Álgebra, Aritmética e Geometria.

\section{O LABORATÓRIO DE ENSINO DE TRIGONOMETRIA: CONCEITOS E EXPERIMENTAÇÕES}

Em 2018, como forma de atualizar o PPP do curso de licenciatura em Matemática da UECE, pautado nas novas e nas velhas normas governamentais ${ }^{4}$, o fluxo passou de 2924 (duas mil novecentas e vinte e quatro) horas, em 2008, para 3230 (três mil, duzentas e trinta) horas em 2018, ocasionando assim, na ampliação das disciplinas que contemplam práticas pedagógicas como os laboratórios de Matemática. Nesse sentido foi agregado disciplinas de Laboratórios de Ensino de Matemática nas quatro áreas centrais: Trigonometria, Geometria, Aritmética e Álgebra, ou seja, 34 horas/aulas, totalizando 102 horas/aulas nesse componente curricular.

Uma das disciplinas propostas, é o LET que é ofertada no segundo semestre, contemplado 20 vagas semestrais e possui pré-requisito as disciplinas de Geometria Plana, e Conjuntos e Funções. Sua ementa está pautada em estudar:

O papel do laboratório no ensino e na aprendizagem de conceitos de trigonometria. Teoria e prática de conteúdos trigonométricos para a educação básica. Confecção de materiais didáticos manipuláveis e desenvolvimento de propostas de atividades para

\footnotetext{
${ }^{4}$ Para conhecer essas normas vide Ceará (2018, p. 6-7). 
o ensino básico. Planejamento e realização de uma experiência prática com o uso de materiais concretos no ensino básico. (CEARÁ, 2018, p. 83)

No que se refere a confecção dos materiais didáticos manipuláveis mencionado em Ceará (2018), ele tem o intuito de construir artefatos de baixo custo, como quebra-cabeças planos e jogos matemáticos. Vinculado a esse material, propor uma sequência didática e/ou atividades também faz parte dessa transformação prática, contribuindo para a aplicabilidade em sala de aula, por meio da confecção de guia para o professor da Educação básica.

No que se refere a referências bibliográficas, percebe-se uma atualização das publicações, tendo obras nacionais e internacionais, tais como: Klein (2009), Fonseca (2010), Guelli (2003), Kennedy (1992), Morey (2003), Morey e Mendes (2011), Pereira (2012), Van Brummelen (2009, 2013) Lorenzato (2006), Rêgo e Rêgo (2000), e Rodrigues e Gazire (2015).

Partindo desses direcionamentos e propondo uma experiência que visava romper com as fronteiras da sala de aula, em 2020, ano de primeira oferta da disciplina, deparou-se com a pandemia do COVID-19, sendo realizada uma restruturação do planejamento, inicialmente pensado presencialmente, para que as atividades pudessem ser realizadas de forma remota. Basicamente foi utilizada a plataforma do Google Meet e Zoom, Blog da disciplina ${ }^{5}$, grupo de WhatsApp e e-mail. Assim, a seguir, será apresentado o planejamento da disciplina de LET, disponibilizados para as turmas do curso de licenciatura em Matemática da UECE matriculados em $2020^{6}$.

\section{Modelo de PROPOSTA DE LABORATÓRIO DE ENSINO DE TRIgONOMETRIA}

Partindo do programa da disciplina de LET pensou-se em uma abordagem no qual a teoria e a prática permeassem todo o processo de ensino e de aprendizagem desses futuros professores de Matemática. Dessa forma, das 34 horas/aulas disponíveis, dividiu-se os 17 encontros da seguinte maneira:

\footnotetext{
${ }^{5}$ https://acarolinacp.blogspot.com/p/disciplina-laboratorio-de-ensino-de.html

6 No ano de 2020 foram ofertados, nos cursos presenciais, os semestres de 2019.2 e 2020.1 devido a greves, paralizações e até mesmo a pandemia. Dessa forma, o calendário acadêmico da UECE está desregulado em relação ao ano civil.
} 
Quadro 1 - Síntese dos momentos da disciplina de LET

\begin{tabular}{|c|c|c|}
\hline & Aulas & Conteúdos propostos \\
\hline \multirow{6}{*}{ } & 1 & Pesquisa sobre o ensino de Trigonometria \\
\hline & 2 & Panorama da história da Trigonometria \\
\hline & 3 & Ensino de Trigonometria no Brasil \\
\hline & 4 & Ensino de Trigonometria e recursos didáticos \\
\hline & 5 & Papel, perspectiva e utilização do LET \\
\hline & 6 & Teoria e prática de conteúdos trigonométricos para a Educação básica \\
\hline \multirow{11}{*}{ : } & 7 & Vivenciando uma prática laboratorial com conteúdos trigonométricos \\
\hline & 8 & Vivenciando uma prática laboratorial com conteúdos trigonométricos \\
\hline & 9 & Prática LET \\
\hline & 10 & Prática LET \\
\hline & 11 & Prática LET \\
\hline & 12 & Prática LET \\
\hline & 13 & Prática LET \\
\hline & 14 & Prática LET \\
\hline & 15 & Prática LET \\
\hline & 16 & Prática LET \\
\hline & 17 & Prática LET \\
\hline
\end{tabular}

Fonte: Elaborado pelas autoras.

Conforme descrito no quadro 1, aproximadamente $64,7 \%$ da carga horária está destinada a vivencias envolvendo práticas laboratoriais sobre conteúdos trigonométricos, nos quais são aplicados dois exemplos de práticas envolvendo material manipulativos e/ou tecnológico confeccionado pelo docente da disciplina, de modo a permitir aos alunos uma vivência desse momento e exemplificar os instrumentais que serão utilizados no decorrer das práticas por eles elaboradas: guia do professor e a folha do aluno.

Em relação as práticas promovidas pela docente da disciplina, como exemplos norteadores das demais, tratou-se de objetos do conhecimento presentes em Trigonometria. No entanto, vale ressaltar, que em Brasil (2018), na BNCC, não existe unidade temática intitulada por Trigonometria, mas os conteúdos desta, encontram-se em Geometria (ensino fundamental final) e Geometrias e medidas (ensino médio).

A primeira prática é intitulada "Estudando razões trigonométricas por meio do geoplano isométrico e quadrangular" e tinha como objeto de conhecimento, a ampliação e redução de figuras poligonais em malhas quadriculadas, reconhecendo a congruência dos ângulos e a proporcionalidade dos lados correspondentes. Também é citada a habilidade EF05MA18 da BNCC (BRASIL, 2017, p. 196): "Reconhecer a congruência dos ângulos e a proporcionalidade entre os lados correspondentes de figuras poligonais em situações de ampliação e de redução em malhas quadriculadas e usando tecnologias digitais". 
Em suma, essa prática visava que, experimentalmente, os alunos fossem expostos ao significado de seno, cosseno e tangente por meio das relações trigonométricas de um triângulo retângulo para os ângulos de $30^{\circ}, 45^{\circ}$ e $60^{\circ}$ (ângulos notáveis). Esses conceitos foram estudados por meio dos geoplanos, isométrico e quadrangular, a partir do triângulo equilátero e do quadrado, construídos com ligas coloridas no material concreto ${ }^{7}$. Considerou-se como objetivo da prática, conceituar e determinar as razões trigonométricas dos ângulos de $30^{\circ}, 45^{\circ}$ e $60^{\circ}$, direcionando 3 horas/aulas para a aplicação dessa experiência. É importante ressaltar que conceitos envolvendo teorema de Pitágoras; conceitos e características do quadrado; conceitos e características do triângulo isósceles e equiláteros; e extrair raiz quadrada sem calculadora, são pré-requisitos para o aluno desenvolver a prática.

A segunda prática era intitulada "Em busca do destino correto com a balhestilha" e tinha como objeto de conhecimento as relações trigonométricas em um triângulo retângulo, em específico, o conceito de tangente. Relacionando com a habilidade presente na BNCC, ela perfaz a EM13MAT306 que é

resolver e elaborar problemas em contextos que envolvem fenômenos periódicos reais, como ondas sonoras, ciclos menstruais, movimentos cíclicos, entre outros, e comparar suas representações com as funções seno e cosseno, no plano cartesiano, com ou sem apoio de aplicativos de álgebra e geometria (BRASIL, 2018, p. 528).

Sua sinopse está direcionada a um experimento que consiste em uma situação problema que envolve o uso de um instrumento náutico do século XVII, denominado por balhestilha, mediante o naufrágio de um navio. Assim, por meio do desenvolvimento desse problema os alunos podem vivenciar uma situação próxima do século XVII em pleno as grandes navegações e identificar conhecimentos trigonométricos que se encontram incorporados no instrumento, em especial, o conceito de tangente de um ângulo interno a um triângulo retângulo.

Considerou-se como objetivos da segunda prática, vivenciar uma situação problema, envolvendo a balhestilha e seu uso; identificar os conhecimentos trigonométricos que estão incorporados no instrumento e no seu uso durante as medições dos astros; e formalizar o conceito tangente implicado no uso do instrumento. A docente direcionou 2 horas/aulas para sua aplicação dessa experiência. É importante observar que alguns conhecimentos, tais como noção de ângulo; arco de circunferência; ângulo central; e medida de arco de circunferência, devem já ter sido previamente estudados pelo aluno.

\footnotetext{
${ }^{7}$ Como recurso tecnológico utilizamos os objetos de aprendizagem expostos em sites. No caso do geoplano isométrico foi utilizado: https://www.geogebra.org/m/k3ZTOD0Z. E o geoplano quadrangular foi usado o https://apps.mathlearningcenter.org/geoboard/. Ambos acessados em 29 maio de 2021.
} 
Essas práticas foram construídas a partir de um modelo de planejamento confeccionado pelos docentes da disciplina que inclui o guia do professor e a folha do aluno. No que se refere a guia do professor (Figura 1), pensou-se em um primeiro momento, aspectos mais gerais:

- Informações gerais sobre o experimento, vinculadas aos documentos oficiais: nome e foto do material do experimento, Unidade Temática, Objeto de conhecimento e habilidades, todas de acordo com a BNCC;

- Aspectos gerais do experimento: sinopse, objetivo(s), conhecimentos prévios e duração.

Figura 1 - Modelo de estrutura do Guia do Professor

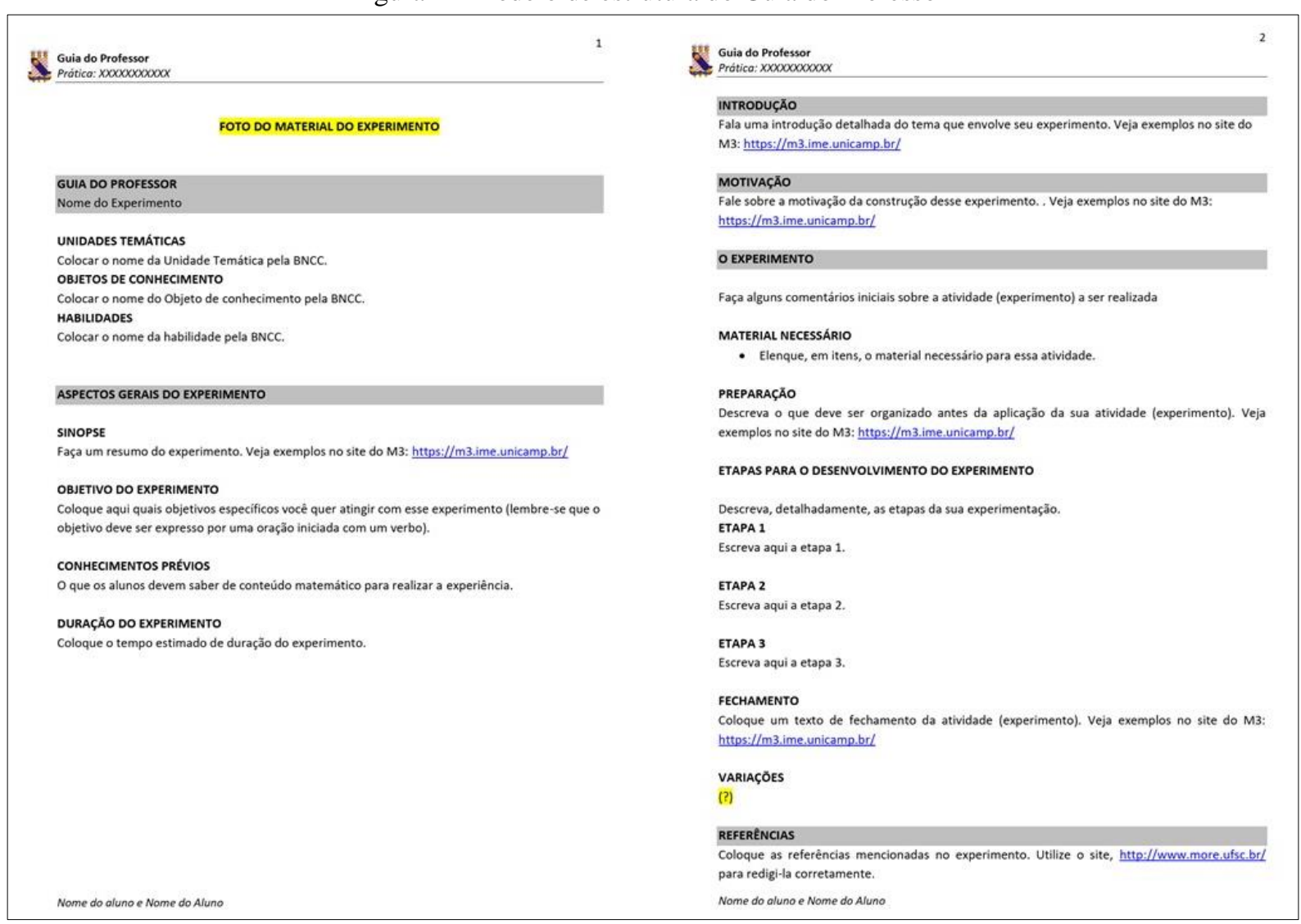

Fonte: Elaborada pelas autoras.

O segundo momento é algo mais descritivo, no qual é composto por uma breve introdução do experimento, motivações em produzir um material para esse conteúdo, descrição detalhada trazendo os materiais necessários para o desenvolvimento da prática, a preparação do material, no qual é descrito o que deve ser organizado antes da aplicação do experimento, o detalhamento das etapas para o desenvolvimento da ação, as variações de propostas, um fechamento para essa prática e as referências utilizadas.

No que se refere a folha do aluno (Figura 2), é inicialmente feito os comentários iniciais que introduzam o aluno na atividade. Pode ser questões em torno da problemática abordada 
pelo experimento, ou colocações iniciais sobre o que será visto, entre outros. Em seguida é exporto os procedimentos do experimento, ou seja, a descrição do passo-a-passo, com detalhes, o que deve ser feito pelo aluno antes e durante sua execução.

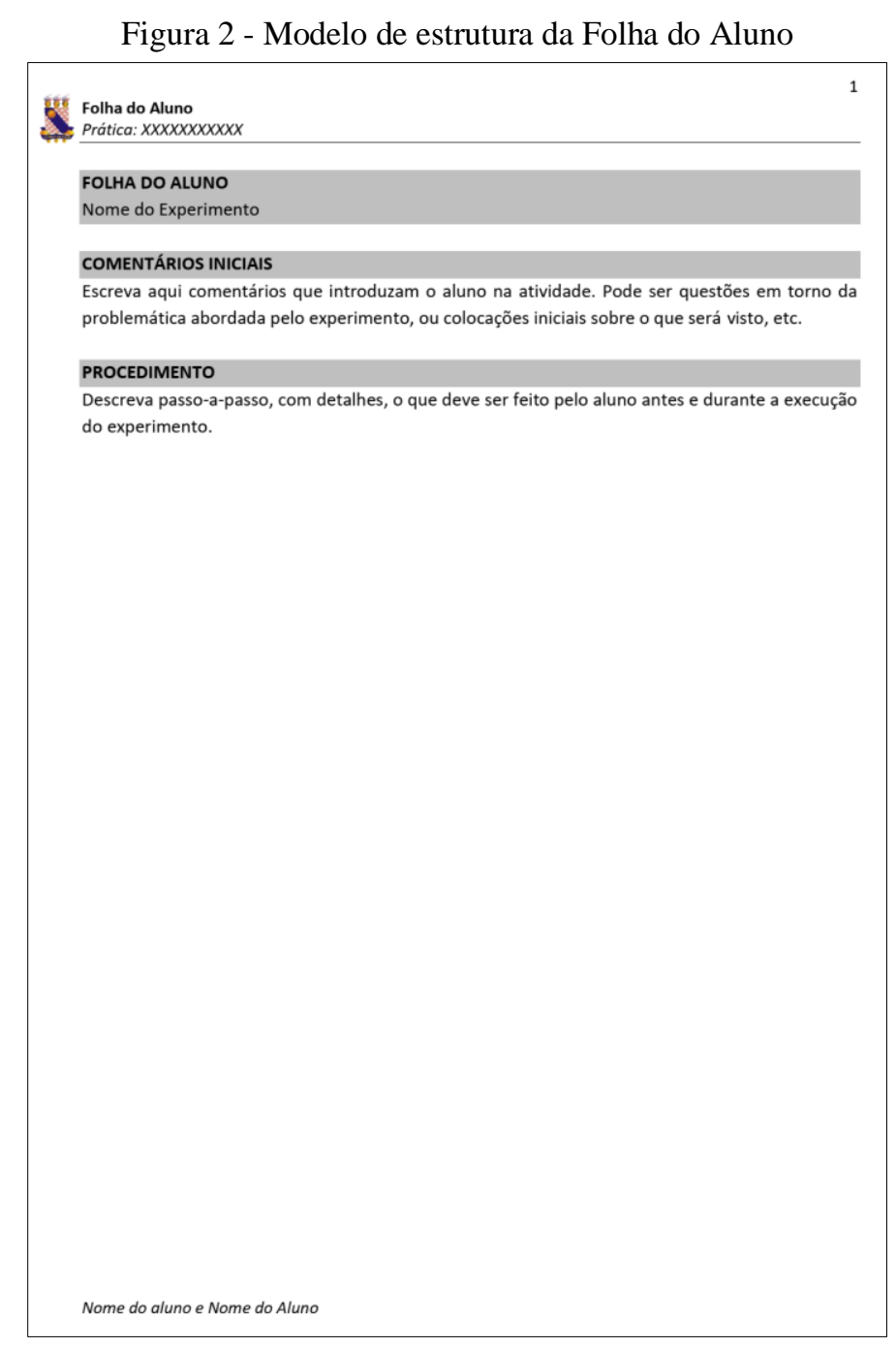

Fonte: Elaborado pelas autoras.

Ressalta-se que esse modelo de experimento é uma adaptação e melhoramento do exposto no site da coleção Matemática Multimídia ${ }^{8}$, que contém um conjunto com mais de 300 recursos educacionais de Matemática para o Ensino Médio, proposto pela Universidade de Campinas (Unicamp).

\section{O LÓCUS DA PESQUISA E SUAS PRODUÇÕES COLETIVAS}

Diante dos detalhamentos apontados anteriormente, segue-se com a pretensão de apresentar o lócus da realização desse estudo, na expectativa de conhecer e perceber os

\footnotetext{
${ }^{8}$ https://m3.ime.unicamp.br/, acessado em 29 de maio de 2021. 
momentos vivenciados nas práticas realizadas no LET, no ano letivo de 2020. Assinalou-se assim, que essa experiência constituiu-se por meio de muitas adaptações, como do ambiente, das ações planejadas, dos recursos, das metodologias, por conta do que o contexto exigia-nos.

E, assim, concorda-se consoante a Stormowski (2018) que essa adaptação, fez-se refletir, que muitas vezes o uso de tecnologias na Educação se destinava-se aos laboratórios de informática de escolas e universidades. E, também, percebe-se que os documentos norteadores do ensino de variadas áreas do conhecimento, como BNCC e PCN, em Brasil (2018) e Brasil (1997), respectivamente, já admitiam essa necessidade de inserção do uso de tecnologias, em algumas vezes sem sucesso, pela ausência de formação de professores para isto.

Nessa compreensão, ver-se que a utilização de TDIC, apesar de recomendada, ainda é muito fragilizada em seu uso, pela falta de formação de professores, para o que Oliveira (2018, p.62) apontou por fluência no uso destas, tendo "um olhar cuidadoso sobre pessoas, tecnologias [...] e suas relações". E, ademais, os participantes da disciplina de LET, na UECE, foram caracterizados como professores em formação inicial de suas carreiras e submetidos a uma experiência de adaptação da ementa e programa de curso nesta modalidade remota.

No ano de 2020, foram executados dois semestres acadêmicos, sendo ofertados a disciplina de LET, nos turnos de tarde e noite, em que foram executados nestes semestres de 2019.2 e 2020.1, respectivamente, um total de sete (tarde), oito (noite), sete (tarde) e seis (noite) práticas, sendo estruturados a seguir no (quadro 2), por título das práticas que foram realizadas, o objeto do conhecimento, que refere-se aos conteúdos tratados e a categoria de classificação dos recursos produzidos e usados nas aulas de LET. 
Quadro 2 - Descrição das práticas de ensino de LET - 2019.2

\begin{tabular}{|c|c|c|}
\hline \multicolumn{3}{|c|}{ Práticas de Laboratório de Ensino de Trigonometria - Semestre 2019.2 (Tarde) } \\
\hline Título da prática & Objeto do conhecimento & Categoria $^{9}$ \\
\hline A Roda Gigante & Gráficos das funções periódicas de seno e cosseno & MDM \\
\hline Angle & Redução ao primeiro quadrante & MDD \\
\hline Círculo dos Triângulos & Construção do triângulo no círculo trigonométrico & MDM \\
\hline $\begin{array}{l}\text { Dominando o ciclo } \\
\text { trigonométrico }\end{array}$ & $\begin{array}{l}\text { Ângulos notáveis e relações trigonométricas de seno, } \\
\text { cosseno e tangente no triângulo retângulo }\end{array}$ & MDM \\
\hline $\begin{array}{l}\text { Geoplano } \\
\text { Quadrangular }\end{array}$ & $\begin{array}{l}\text { Razões trigonométricas seno e cosseno no triângulo } \\
\text { retângulo }\end{array}$ & MDM \\
\hline $\begin{array}{l}\text { Jogo da } \\
\text { Trigonomemória }\end{array}$ & Círculo trigonométrico e redução ao primeiro quadrante & MDM \\
\hline Memorângulo & Funções trigonométricas & MDM \\
\hline \multicolumn{3}{|c|}{ Práticas de Laboratório de Ensino de Trigonometria - Semestre 2019.2 (Noite) } \\
\hline $\begin{array}{l}\text { Batalha Naval } \\
\text { Trigonométrico }\end{array}$ & $\begin{array}{l}\text { Ângulos notáveis e razões trigonométricas no círculo } \\
\text { trigonométrico }\end{array}$ & MDM \\
\hline Dama trigonométrica & $\begin{array}{l}\text { Relações trigonométricas no triângulo retângulo e ângulos } \\
\text { notáveis }\end{array}$ & MDM \\
\hline Dominó trigonométrico & Funções trigonométricas e ângulos notáveis & MDM \\
\hline Jogo dos Senos & $\begin{array}{l}\text { Relações trigonométricas em um triângulo e ângulos } \\
\text { notáveis (função seno) }\end{array}$ & MDM \\
\hline Ludo Trigonométrico & Razões trigonométricas e ângulos notáveis & MDM \\
\hline Roleta trigonométrica & Círculo trigonométrico & MDM \\
\hline Trilha trigonométrica & $\begin{array}{l}\text { Ângulos notáveis e relações trigonométricas no triângulo } \\
\text { retângulo }\end{array}$ & MDM \\
\hline Vicmetro & Razões trigonométricas (seno, cosseno e tangente) & MDD \\
\hline
\end{tabular}

Fonte: Elaborada pelas autoras

Nas práticas realizadas, no semestre de 2019.2, viu-se a recorrência de produções e utilizações de materiais didáticos manipulativos (MDM), que referiam-se a recursos com caráter de suporte didático, como por exemplo, a construção manual de um círculo trigonométrico para uma das aulas de LET, com materiais concretos e, ainda existiram, os MDM que se caracterizavam como jogos didáticos produzidos para fins educacionais de Trigonometria. Além destes, experimentou-se, também, materiais didáticos digitais (MDD), que caracterizaram-se de maneira correspondente, mas tendo o caráter digital, como o caso, de um aplicativo para android ${ }^{10}$.

De maneira correspondente, ao discutido anteriormente, debruçou-se a verificar e analisar as práticas de ensino de LET do semestre de 2020.1, nos turnos tarde e noite, conforme ofertados as disciplinas. Visualizou-se que das 13 práticas executadas nesta ocasião, a maioria correspondeu também, ao uso de MDM para trabalhar com o ensino de variados conceitos trigonométricos representados no (quadro 3) nos objetos de conhecimentos.

\footnotetext{
${ }^{9}$ MDM: Material Didático Manipulável; MDD: Material Didático Digital

${ }^{10}$ Para mais informações vide: https://pt.wikipedia.org/wiki/Android
} 
Quadro 3 - Descrição das práticas de ensino de LET - 2020.1

\begin{tabular}{|c|c|c|}
\hline \multicolumn{3}{|c|}{ Práticas de Laboratório de Ensino de Trigonometria - Semestre 2020.1 (Tarde) } \\
\hline Título da prática & Objeto do conhecimento & Categoria \\
\hline Stop Trigonométrico & Arcos côngruos e reduções & MDM \\
\hline Vicmetro & Razões trigonométricas & MDD \\
\hline $\begin{array}{l}\text { Trigonometrando no } \\
\text { tabuleiro }\end{array}$ & Seno, cosseno e tangente & MDM \\
\hline $\begin{array}{l}\text { Círculo } \\
\text { trigonométrico } \\
\text { manual } \\
\end{array}$ & Círculo trigonométrico (seno e cosseno) & MDM \\
\hline $\begin{array}{l}\text { Charada } \\
\text { trigonométrica }\end{array}$ & $\begin{array}{l}\text { Relações fundamentais da Trigonometria e relações } \\
\text { trigonométricas no triângulo retângulo }\end{array}$ & MDD \\
\hline $\begin{array}{l}\text { Roda gigante } \\
\text { trigonométrica }\end{array}$ & $\begin{array}{l}\text { Relações entre arcos e ângulos notáveis no círculo } \\
\text { trigonométrico }\end{array}$ & MDM \\
\hline $\begin{array}{l}\text { Dimensionar ângulos } \\
\text { por meio de } \\
\text { triângulos }\end{array}$ & Relações trigonométrica no triângulo & MDM \\
\hline \multicolumn{3}{|c|}{ Práticas de Laboratório de Ensino de Trigonometria - Semestre 2020.1 (Noite) } \\
\hline Roleta trigonométrica & $\begin{array}{lllll}\begin{array}{l}\text { Círculo trigonométrico, } \\
\text { trigonométricas }\end{array} & \text { arcos côngruos } & \text { razões } \\
\end{array}$ & MDM \\
\hline $\begin{array}{l}\text { Medição de alturas } \\
\text { com astrolábio }\end{array}$ & Funções trigonométricas & MDD \\
\hline 21 trigonométrico & Relações trigonométricas nos triângulos & MDM \\
\hline $\begin{array}{l}\text { Prancha } \\
\text { trigonométrica }\end{array}$ & Funções seno, cosseno e tangente no círculo trigonométrico & MDM \\
\hline $\begin{array}{l}\text { Jogo de cartas } \\
\text { tronométrica }\end{array}$ & Seno, cosseno e tangente & MDM \\
\hline Procurando o radiano & Funções trigonométricas (seno e cosseno) & MDM \\
\hline
\end{tabular}

Fonte: Elaborada pelas autoras.

E, assim, diante deste cenário de formação inicial de professores na disciplina de LET, verificou-se nesta modalidade remota, que a maioria dos alunos, optaram pela produção e experimentação de MDM no ensino de Trigonometria, levando-nos a refletir sobre o questionamento apontado por Stormowski (2019, p.93) de se "vale a pena utilizar tecnologias digitais na Educação?”.

E, nessa percepção, Breda (2018) vem reforçar, que a utilização de TDIC no cenário educacional do ensino de Matemática, representam ações significativas, mas para isso é preciso a compreensão de que a incorporação destes recursos afetam e exigem um tratamento didático a ser realizado, através, do planejamento de aulas para o ensino de conceitos matemáticos. E, ver-se que essas mudanças, podem representar alterações importantes, aos discentes e docentes, para vislumbrar novas formas de propor e realizar atividades.

Dessa forma, conforme as categorias de recursos aos quais foram produzidos nos semestres do ano letivo de 2020, identificou-se no de 2019.2, houve uma predominância de 
87\% caracterizados como MDM segundo vistos no gráfico da Figura 3, sendo um total de 13, que entre estes, nove referiam-se a MDM classificados como jogos.

Figura 3 - Categorias dos recursos produzidos para Práticas de LET (2019.2)

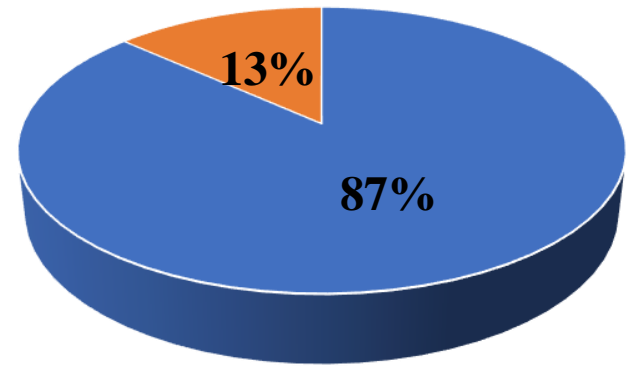

- Material Didático Manipulativo

- Material Didático Digital

Fonte: Elaborado pelas autoras.

Em continuidade e de maneira semelhante, temos a estruturação das categorias dos recursos produzidos e usados nas práticas de ensino de LET do semestre de 2020.1. E, neste, verificou-se que $77 \%$ destes correspondiam a MDM, sendo um total de 10, em que destes três referiam-se a MDM classificados como jogos e 23\% de MDD, conforme visto no gráfico 2.

Figura 4 - Categorias dos recursos produzidos para Práticas de LET (2020.1)

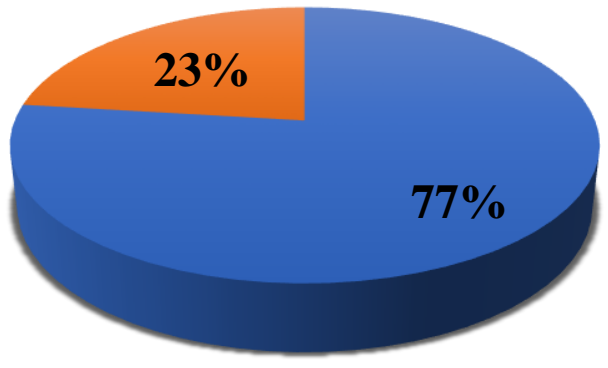

Material Didático

Manipulatico

- Material Didático

Digital

Fonte: Elaborado pelas autoras.

Dessa maneira, viu-se mediante a recorrência de produções de MDM em relação a elaboração, construção e experimentação de MDD, que possivelmente se deu pelos desafios da inserção e utilização de TDIC no ensino de Matemática, destacando a necessidade do que Oliveira (2018) ressaltou a importância da fluência no uso de tecnologias digitais.

\section{NOTAS FINAIS}

Concluímos que o ensino remoto da disciplina de LET, ocorrida durante o ano letivo de 2020, no contexto histórico da pandemia de COVID 19, ofertada e executada no curso de licenciatura em Matemática da UECE, com professores em formação inicial, apontou algumas 
fragilidades quanto ao ensino e aprendizagem de conceitos trigonométricos e, também, destacou a falta de preparo destes sujeitos quanto a utilização de ferramentas tecnológicas.

Nesta ocasião, percebeu-se a relevância da compreensão e reflexão de quando e como utilizar o ambiente computacional para o ensino de conceitos matemáticos. Isso ocorreu, principalmente, quando se exigiu por conta do cenário vivenciado, algumas adaptações da ementa e programa da disciplina, que seriam executadas em ambiente físico do Laboratório de Ensino de Matemática (LEM), mas que se adaptou para o ambiente virtual fornecido no Google Meet e Zoom a partir do contexto.

Além disso, viu-se que a metodologia orientadora subsidiou o tripé pretendido a ser desenvolvido no percurso desta, referindo-se a planejamento, recursos e metodologias. Está amparou-nos na estruturação das aulas de LET, propondo durante as práticas, o avanço cognitivo dos sujeitos deste estudo, sendo contemplado diante dos recursos a experimentação de sequências didáticas, que permitiam a tomada de posição, maturação, solução e prova das práticas propostas.

Por fim, observou-se nas práticas de LET, que os professores de Matemática presentes nesta experiência, tinham também, dificuldades quanto a parte conceitual de Trigonometria. E, tais informações, foram identificadas, a partir das produções destes, em relação aos guias do professor, folhas do aluno e práticas executadas na disciplina.

\section{REFERÊNCIAS}

ARAÚJO, Jussara de Loiola; BORBA, Marcelo C. Construindo pesquisas coletivamente em Educação Matemática. In: FIORENTINI, Dario; GARNICA, Antonio Vicente M.; BICUDO, Maria Aparecida V. (Orgs.). Pesquisa Qualitativa em Educação Matemática. 2. ed. Belo Horizonte: Autêntica, 2004. cap. 2 e 4, p. 49-78, p. 101-114.

BERTONI, Nilza Eigenheer; GASPAR, Maria Terezinha Jesus. Laboratório de ensino de Matemática da Universidade de Brasília - uma trajetória de pesquisa em Educação Matemática, apoio à formação do professor e interação com a comunidade. In: LORENZATO, Sérgio (Org). Laboratório de Ensino de Matemática na formação de professores. Campinas: Autores Associados, 2006. p. 135-152.

BITTAR, Marilena; FREITAS, José Luiz M. Laboratórios de educação matemática. In: BITTAR, Marilena; FREITAS, José Luiz M. (Ed.). Fundamentos e metodologia de matemática para os ciclos iniciais do ensino fundamental. Campo Grande: Editora UFMS, 2005. p. 231-265.

BRASIL. Diretrizes Curriculares Nacionais para os Cursos de Matemática, Bacharelado e Licenciatura. Brasília: Conselho Nacional de Educação / Câmara de Educação Superior, 2001. 
BRASIL. Ministério da Educação. Base Nacional Comum Curricular (BNCC). Educação é a Base. Brasília, MEC/CONSED/UNDIME, 2017.

BRASIL. Ministério da Educação; Secretaria de Educação Básica. Base Nacional Comum Curricular. Brasília: MEC/ SEB, 2018.600 p.

BRASIL. Secretaria de Educação Fundamental. Parâmetros curriculares nacionais: Matemática / Secretaria de Educação Fundamental. - Brasília: MEC/SEF, 1997. 142p.

BREDA, Adriana. O ensino de Matemática e o uso das TIC. In: SILVA, Rodrigo Sychocki da (Org.). Diálogos e Reflexões sobre tecnologias digitais na Educação Matemática. São Paulo: Editora Livraria da Física, 2018.

CEARÁ. Curso de Licenciatura em Matemática - Projeto Pedagógico do Curso. UECE: Fortaleza, 2018

CEARÁ. Projeto Político Pedagógico do Curso de Licenciatura em Matemática. UECE: Fortaleza, 2007.

EVES, Howard W. Introdução à História da Matemática. Tradução: Hygino H.

Domingues. Campinas: Editora da Unicamp, 1995.

FARMER, David W. Grupos e Simetria. Lisboa: Gradiva, 1996.

FONSECA, Laerte Silva da. Aprendizagem em Trigonometria: obstáculos, sentido e mobilizações. Aracajú - SE: Editora UFS, 2010.

GUELLI, Oscar. Contando a História da Matemática: Dando Corda na Trigonometria. São Paulo, SP: Editora Ática, 2003.

JAVARONI, Sueli Liberatti; ZAMPIERI, Maria Teresa. Tecnologias Digitais nas aulas de Matemática: um panorama acerca das escolas públicas do Estado de São Paulo. 2 ed. São Paulo: Livraria da Física, 2019.

KENNEDY, Edward S. Tópicos de História da Matemática para uso em sala de aula. Trigonometria. NCTM, 1969. Tradução Hygino H. Domingues. Atual: São Paulo,1992.

KLEIN, Felix. Matemática Elementar de um Ponto de Vista Superior: Trigonometria. Lisboa: Sociedade Portuguesa de Matemática, 2009.

LORENZATO, Sérgio. Laboratório de Ensino de Matemática na formação de

Professores. Campinas, SP: Autores Associados, 2006. (Coleção Formação de Professores).

MOREY, Bernadete. Geometria e Trigonometria na Índia e nos Países Árabes. Coleção História da Matemática para Professores, Rio Claro, SP: SBHMat, 2003.

MOREY, Bernadete; MENDES, Iran Abreu. História da matemática para professores: Conhecimentos matemáticos na época das navegações. Natal: Sociedade Brasileira de História da Matemática, 2011. 
OLIVEIRA, Gerson Pastre. Sobre tecnologias e educação Matemática - fluência, convergência e o que isto tem a ver com aquilo. In: OLIVEIRA, Gerson Pastre; ALMOULOUD, Saddo Ag; SILVA, Maria José Ferreira da; COUTINHO, Cileda Queiroz; GAITA, Cecília. Educação Matemática: epistemologia, didática e tecnologia. São Paulo: Editora Livraria da Física, 2018.

OLIVEIRA, Zaqueu Vieira; KIKUCHI, Luzia Maya. O laboratório de matemática como espaço de formação de professores. Cad. Pesqui., São Paulo, v. 48, n. 169, p. 802-829, Sept. 2018.

PEREIRA, Cícero da Silva. Aprendizagem em Trigonometria no Ensino Médio. Jundiaí SP: Paco Editorial, 2012.

PINHEIRO, Ana Cláudia Mendonça. Concepção e desenvolvimento de uma formação continuada de professores de Matemática baseada na Sequência Fedathi. 2016. 135f. Tese (Programa de Pós-graduação em Educação) - Universidade Federal do Ceará - UFC, Fortaleza, 2016.

PINHEIRO, Ana Cláudia Mendonça; BORGES NETO, Hermínio; PINHEIRO, Tânia Saraiva de Melo. Quando e como utilizar o Ambiente Computacional para o Ensino de Conceitos Matemáticos: uma proposta de organização do trabalho docente. In: SANTOS, Alice Nayara dos; ROGÉRIO, Pedro. (Orgs.). Currículo: diálogos possíveis. Fortaleza: Edições UFC, 2013. p. 149-164.

PINHEIRO, Ana Cláudia Mendonça; PEDROSA, Virlane Nogueira Melo; MENDONÇA, Adriana Ferreira. Uma proposta metodológica do uso do ambiente computacional como recurso didático para o ensino de conceitos matemáticos baseados na Sequência Fedathi. In: Encontro Nacional de Educação Matemática (ENEM). Anais [...] São Paulo, 2016.

RÊGO, Rogéria G., RÊGO, Rômulo M. Matematicativa. João Pessoa, PB: EdUFPb, 2000.

RODRIGUES, Fredy C. Laboratório de educação matemática: descobrindo as potencialidades do seu uso em um curso de formação de professores. 2011. $195 \mathrm{f}$. Dissertação (Mestrado) - Pontifícia Universidade Católica de Minas Gerais, Belo Horizonte, 2011.

RODRIGUES, Fredy Coelho; GAZIRE, Eliane Sheid. Laboratório de Educação Matemática na formação de Professores. Curitiba: Appris, 2015.

SMITH, Kurt. Matemática Divertida: Truques de Lógica Matemática. Lisboa: Editora Replicação, 1996.

SOUZA, Giselle Costa de. Reflexões sobre aliança entre HM, TDIC e IM. In: SOUZA, Giselle Costa de (Org.). Aliança entre História da Matemática e Tecnologias via Investigação Matemática: reflexões e práticas. São Paulo. Editora Livraria da Física, 2020.

STORMOWKI, Vandoir. Vale a pena utilizar tecnologias digitais na educação?. In: SILVA, Rodrigo Sychocki da (Org.). Diálogos e Reflexões sobre tecnologias digitais na Educação Matemática. São Paulo: Editora Livraria da Física, 2018. 
TURRIONI, Ana Maria S. O laboratório de educação matemática na formação inicial de professores. 2004. 163 f. Dissertação (Mestrado) - Universidade Estadual Paulista "Júlio de Mesquita Filho", Rio Claro, 2004.

VAN BRUMMELEN, Glen. Heavenly Mathematics: The Forgotten Art of Spherical Trigonometry. Princeton, New Jersey: Princeton University Press, 2013.

VAN BRUMMELEN, Glen. The Mathematics of the Heavens and the Earth: The Early History of Trigonometry. New Jersey: Princeton University, 2009.

VAN CLEAVE, Janice. Matemática para Jovens. Lisboa: Dom Quixote, 1994. 